\title{
Article \\ Error Evaluation and Suitability Assessment of Common Reliability Methods in the Case of Shallow Foundations
}

\author{
Filip Dodigović ${ }^{1}$ (D), Krešo Ivandić ${ }^{1, *}$, Meho Saša Kovačević ${ }^{2}$ and Božo Soldo ${ }^{3}$ \\ 1 Faculty of Geotechnical Engineering, University of Zagreb, 42000 Varaždin, Croatia; \\ filip.dodigovic@gfv.unizg.hr \\ 2 Faculty of Civil Engineering, University of Zagreb, 10000 Zagreb, Croatia; msk@grad.hr \\ 3 Department of Civil Engineering, University North, 42000 Varaždin, Croatia; bozo.soldo@unin.hr \\ * Correspondence: kreso.ivandic@gfv.unizg.hr; Tel.: +385-91-591-83-36
}

Citation: Dodigović, F.; Ivandić, K.; Kovačević, M.S.; Soldo, B. Error

Evaluation and Suitability

Assessment of Common Reliability Methods in the Case of Shallow Foundations. Appl. Sci. 2021, 11, 795. https://doi.org/10.3390/app 11020795

Received: 10 December 2020 Accepted: 13 January 2021 Published: 15 January 2021

Publisher's Note: MDPI stays neutral with regard to jurisdictional clai$\mathrm{ms}$ in published maps and institutional affiliations.

Copyright: $\odot 2021$ by the authors. Licensee MDPI, Basel, Switzerland. This article is an open access article distributed under the terms and conditions of the Creative Commons Attribution (CC BY) license (https:// creativecommons.org/licenses/by/ $4.0 /)$.

\begin{abstract}
A geotechnical structure's reliability index calculated using identical input parameters and assumptions can significantly vary as a function of the used method. The different approaches to solving the reliability problem could result in an error which depends on many factors. The most important error sources are the complexity of the performance function, the number of random variables, their mutual correlations, and marginal statistical distributions. A review of relevant literature in the field of reliability in geotechnical engineering revealed a lack of information on the errors of individual reliability methods for geotechnical problems and general criteria for assessing their suitability concerning the error size. The paper defines the reliability method error and proposes criteria for assessing the suitability of reliability methods in geotechnical engineering. Based on the proposed criteria, the suitability of common reliability methods was evaluated in the example of a shallow foundation, analysed according to Eurocode 7, DA 3, such that $E_{d}=R_{d}$. It is shown that due to the mathematically complex expression of the reliability integral, methods that are easier to use result in a larger error and are not suitable for a reliability analysis of shallow foundations. Sophisticated methods are more accurate but require specific knowledge and resources that are not often used in daily engineering practice.
\end{abstract}

Keywords: reliability methods; reliability method error; reliability index; probability of failure; shallow foundation; Eurocode 7; reliability integral; geotechnical engineering

\section{Introduction}

In general, the value of the reliability index of a geotechnical structure, calculated using identical input parameters and assumptions, can vary significantly as a function of the applied method. The main reasons for this are related to assumptions and simplifications, which are introduced in the methods to simplify the reliability analysis. In other words, it is necessary to evaluate the reliability methods accuracies, i.e., research their suitability for application in different types of problem. Because of the differences in the mathematical expressions of the limit state definition among various geotechnical tasks, i.e., different forms of the performance function, it is not possible to give a generalized assessment of the suitability of a particular method of reliability to all geotechnical problems. However, it can be done on a case-by-case basis. The other possibility could be that a single method is suitable for application to a group of mathematically similar problems.

The main goal of this paper is to assess the suitability of common reliability methods in the case of the ultimate limit state (ULS) of shallow foundations. The suitability of the following methods was assessed: Analytical First Order Second Moment (FOSM) method, Taylor Series, Point Estimate Method (PEM), First Order Reliability (FORM) method, Simplified FORM, and the Monte Carlo method. For this purpose, the following sub-goals were set: 
- test the hypothesis of whether the factor of safety (FS) follows normal or lognormal distribution;

- probability method error definition;

- defining the criteria for method suitability assessment.

Analytical FOSM, Taylor Series and PEM reliability methods use FS as an objective function to calculate the reliability index, and their accuracy depends greatly on the assumed statistical distribution of FS. The paper analyses the statistic characteristics of the performance function, and shows that, contrary to a common assumption, the FS in the case of this study is not normally or lognormally distributed. In order to quantify the error which arises from the incorrect assumption of the FS statistical distribution, its actual probability density functions (PDF) were created using the Monte Carlo method. The results obtained were fitted with normal and lognormal PDFs, and error sizes were estimated based on the obtained results.

A review of relevant literature in the field of reliability in geotechnical engineering revealed a lack of information on the reliability method's accuracy and the statistical distribution of the performance function in the case of the ultimate limit state (ULS) of a shallow foundation. Generally, a criterion to estimate the suitability of one or another reliability method for application in geotechnical engineering tasks was not defined. This paper defines such a criterion, based on the error size of the calculated reliability index ( $\beta$ ). Using the proposed criterion, an assessment of the applicability of reliability methods was made, using a simple example of a centrally loaded foundation. The results obtained were compared to the results from other studies in the available literature: stability of the embankments from [1] and retaining wall reliability [2].

In general, Analytical FOSM, Taylor Series, PEM and FORM methods result in a reliability index, while the Monte Carlo and Direct Integration result in the probability of failure $\left(\mathrm{P}_{\mathrm{f}}\right)$. In order to enable mutual comparisons in error sizes, the results of all methods were reported using a reliability index. The connection between $\beta$ i $P_{f}$ is defined by the following relation [3]:

$$
\beta=-\Phi^{-1}\left(P_{\mathrm{f}}\right),
$$

where

$\Phi^{-1}($.$) 一 the inverse Gaussian distribution$

A detailed description of determining the reliability index using FOSM, PEM, FORM and the Monte Carlo is given in [3]. What is generally emphasized, considering the accuracy aspect of each method, is that each method provides a different level of accuracy. Also stated is the problem of the statistical distribution of the performance function. In conclusion, it is reasonable and conservative to assume that it is distributed normally for safety margin (M), and lognormally for the factor of safety (FS).

Fenton and Griffiths [4] conduct analyses of reliability in various geotechnical problems, using FORM, PEM, FOSM and the Monte Carlo methods. In the FOSM and PEM analyses, lognormally distributed performance functions are used. Using the example of ULS and the serviceability limit state (SLS) of piles subjected to a vertical load, they tested hypotheses that the performance functions are lognormally distributed. The soil's influence on the pile was represented by bilinear springs, and the hypothesis was tested for different values of the coefficients of variations of spring stiffnesses $\left(\mathrm{COV}_{\mathrm{s}}\right)$. The hypothesis was confirmed for the ULS and the SLS, in the case where $\mathrm{COV}_{\mathrm{s}}=0.2$. For greater $\mathrm{COV}_{\mathrm{s}}$ values -0.4 for ULS and 0.5 for SLS - the hypothesis was rejected. They conclude that a possible reason for the rejection in the sensitivity of the goodness-of-fit tests to small discrepancies in the fit, particularly in the tails, and that a lognormal distribution is a reasonable assumption.

Filz and Navin [1] conduct reliability analyses using the stability of column-supported embankments (Case 1) and stability of embankments supported on panels under the side slope (Case 2). In their analyses, they use the Taylor Series method, PEM, Simplified FORM and the Direct Integration method. In the Taylor Series and PEM methods they choose the 
factor of safety (FS) for the performance function, and conduct analyses for the assumption that it is normally (Taylor Series and PEM) and lognormally (Taylor Series) distributed. The results of the conducted analyses are presented in Table 1 . They choose the Direct Integration as the control method, and use it to estimate the accuracy of other methods. As expected the Taylor Series and PEM give a significantly greater error when compared to Simplified FORM. A probable cause for such an error is an incorrect estimate of the statistical distribution of FS, as well as a simplification of the aforementioned methods. Considering the error size, they recommend using the Simplified FORM method exclusively to estimate the reliability in the examined cases. Although the most precise, they do not recommend the Direct Integration method due to its complexity.

Table 1. Results of the reliability analyses of embankments stability for Cases 1 and 2 [1].

\begin{tabular}{ccccc}
\hline \multirow{2}{*}{ Method } & \multicolumn{2}{c}{ Case 1 } & \multicolumn{2}{c}{ Case 2 } \\
\cline { 2 - 5 } & $\mathbf{p}_{\mathbf{f}}[1]$ & $\beta$ & $\mathbf{p}_{\mathbf{f}}[1]$ & $\beta$ \\
\hline Direct Integration & 0.032 & 1.85 & $9 \times 10^{-5}$ & 3.75 \\
Taylor Series, lognormal dist. of FS & 0.0036 & 2.69 & $3 \times 10^{-6}$ & 4.53 \\
Taylor Series, normal dist. of FS & 0.01 & 2.33 & 0.003 & 2.75 \\
PEM, normal dist. of FS & 0.017 & 2.12 & 0.0053 & 2.56 \\
Simplified FORM & 0.024 & 1.98 & $10^{-4}$ & 3.72 \\
\hline
\end{tabular}

Wang and Kulhawy [5] analyse the relation of the reliability index for ULS and SLS of augered cast-in-place piles. They estimate the reliability indexes using FOSM, with the assumption of a lognormally distributed performance function. Due to the fact that the performance function can only assume positive values, and for mathematical convenience, such an assumption is considered reasonable.

Duncan [6] promotes the usage of reliability methods in everyday engineering practices. He presents a procedure for determining the reliability index using the Taylor Series method. For the reliability index calculation, using the retaining wall and the slope stability examples, he assumes a lognormal distribution of the performance function, without assessing the reasonability of such an assumption. He claims there is no proof that the FS is lognormally distributed, but he believes that it is a reasonable approximation.

The accuracy of the Simplified FORM, PEM and Taylor Series methods in the example of sliding and baring capacity (undrained) of retaining wall is assessed by Duncan and Sleep [2]. The results obtained were compared with the results of the Monte Carlo method, which is considered the most accurate of all methods used. PEM analyses were conducted for normal and lognormal distribution of the performance function, and the Taylor Series was used for the normal distribution. The arguments for the choice of the assumptions were not elaborated, and the results are presented in Table 2.

Table 2. Results of reliability analyses of retaining wall [2].

\begin{tabular}{cccccccc}
\hline \multirow{2}{*}{ Method } & \multicolumn{2}{c}{$\begin{array}{c}\text { Sliding on } \\
\text { Sand }\end{array}$} & \multicolumn{2}{c}{$\begin{array}{c}\text { Sliding in } \\
\text { Clay }\end{array}$} & \multicolumn{2}{c}{$\begin{array}{c}\text { Bearing Capacity } \\
\text { (Undrained) }\end{array}$} \\
\cline { 2 - 7 } & $\mathbf{p}_{\mathbf{f}}$ & $\boldsymbol{\beta}$ & $\mathbf{p}_{\mathbf{f}}$ & $\boldsymbol{\beta}$ & $\mathbf{p}_{\mathbf{f}}$ & $\boldsymbol{\beta}$ \\
\hline Monte Carlo, 20,000 simulations & 0.024 & 1.98 & 0.022 & 2.01 & 0.018 & 2.10 \\
Simplified FORM & 0.024 & 1.98 & 0.025 & 1.96 & 0.023 & 2.00 \\
Taylor Series, normal dist. of FS & 0.055 & 1.60 & 0.028 & 1.91 & 0.015 & 2.17 \\
PEM, normal dist. of FS & 0.045 & 1.70 & 0.05 & 1.64 & 0.043 & 1.72 \\
PEM, lognormal dist. of FS & 0.026 & 1.94 & 0.016 & 2.14 & 0.011 & 2.29 \\
\hline
\end{tabular}

Table 2 shows a good agreement between the Monte Carlo method results and the results of other methods. It is assumed that the good agreement is the consequence of the mathematically simple performance functions in the case studied. 
Considering the Monte Carlo method, Phoon [7] claims that it is necessary to conduct $10 / \mathrm{p}_{\mathrm{f}}$ simulations for the coefficient of variation of $\mathrm{p}_{\mathrm{f}}\left(\mathrm{COV}_{\mathrm{pf}}\right)$ to be less than 0.3 . This paper confirms the stated hypothesis, and presents a graphic representation of the relation between the number of simulations and $\mathrm{COV}_{\mathrm{pf}}$.

The statistic characteristics of the performance function in the case of the SLS of the foundation are examined by Zhang and $\mathrm{Ng}$ [8]. They analyse 375 bridge and 300 building settlement examples (SLS). They conclude that the performance function of the SLS of the structures follows a lognormal distribution. This information, along with the information on the distribution of the performance function in the case of ULS of the foundation, can be used for a more comprehensive estimate of foundation reliability.

Except in direct reliability calculations, reliability methods are used as parts of more complex procedures, e.g., in reliability-based optimization (RBO). To simplify the calculation work in RBO, Zhang et al. [9] suggest replacing FORM with the simpler FOSM method. FOSM gives acceptably accurate results in linear performance functions and multivariant normal distribution. In other cases, the error can be large, but they believe that this can be rectified by finding the functional relationship between reliability indexes obtained using FORM $\left(\beta^{\mathrm{F}}\right)$ and FOSM $\left(\beta^{\mathrm{M}}\right)$, which they prove to be highly correlated.

\section{Reliability Theory}

Reliability as it is used in the reliability theory is the probability of an event occurring or the probability of a positive outcome. Evaluating reliability affords a means of assessing the degree of uncertainty involved in geotechnical engineering calculations [2]. The complexity of reliability analysis, and consequently the reduced scope of its application, arises from the mathematical definition of reliability. It is defined as the complement of the probability of failure, which can be written as follows [10]:

$$
\mathrm{P}_{\mathrm{S}}=1-\mathrm{P}_{\mathrm{f}}
$$

where:

$\mathrm{P}_{\mathrm{S}}$-is reliability

$\mathrm{P}_{\mathrm{f}}$-is the probability of failure

The probability of failure as a probabilistic event is mathematically defined by the following equation:

$$
P_{f}=\operatorname{Prob}\{g(X) \leq 0\}=\operatorname{Prob}\{M \leq 0\},
$$

where:

$X$ - is a random vector

$\mathrm{g}(\mathrm{X})$-is the performance function

$\mathrm{M}$-is the safety margin

Equation (3) could be rewritten using the reliability integral as follows:

$$
P_{f}=\int_{g(X) \leq 0} f_{X}(X) d X
$$

where:

$\mathrm{f}_{\mathrm{X}}(\mathrm{x})$-joint probability density function of $\mathrm{X}$

Considering the aforementioned, from a mathematical point of view it can be concluded that the basic task of reliability analysis is to calculate a multidimensional integral with joint $\mathrm{PDF}$ of random variables as integrand, and the integration domain defined by the performance function. The reliability problem containing the joint $\operatorname{PDF}\left(\mathrm{f}_{\mathrm{X}}(\mathrm{x})\right)$ of 2 random variables $(X 1$ and $X 2)$, and performance function $g(X 1, X 2)$ is visualized in Figure 1.

The performance function cuts the joint PDF into two parts. The total volume under the surface equals 1 . The smaller volume represents the probability of failure $\left(\mathrm{P}_{\mathrm{f}}\right)$, and the larger, its complement, the reliability $\left(\mathrm{P}_{\mathrm{S}}\right)$. The complexity of solving Equation (4) depends 
on the integrand, the performance function, and the number of variables. Depending on the degree of complexity and the availability of input data, a reliability integral can be calculated by direct integration of a multidimensional integral, or by using analytical or simulation methods [11].

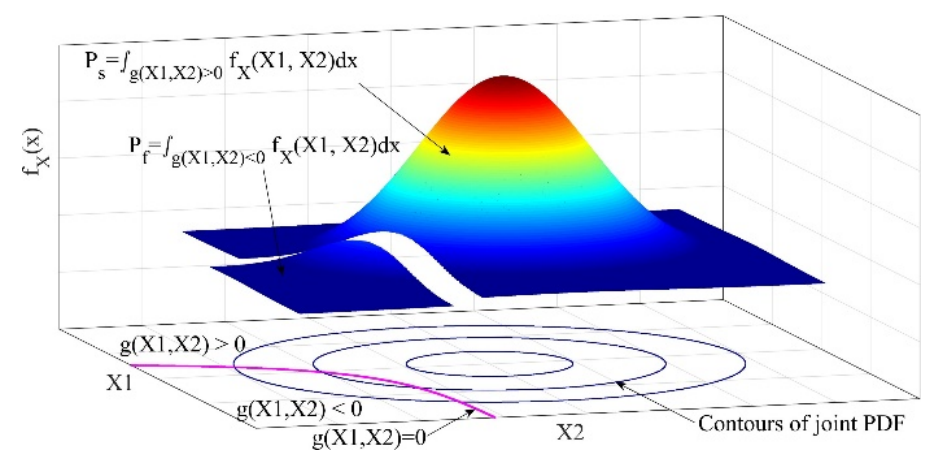

Figure 1. Visualization of a simple reliability problem consisting of 2 random variables, $X 1$ and $X 2$, integrand $\mathrm{f}_{\mathrm{X}}(\mathrm{x})$ and performance function $\mathrm{g}(\mathrm{X} 1, \mathrm{X} 2)$.

\title{
2. Materials and Methods
}

Reliability methods suitability assessments were performed for the ULS (bearing capacity resistance) of a $1.0 \times 1.0 \mathrm{~m}$ centrally loaded square footing embedded in a noncohesive soil at a depth of $1.0 \mathrm{~m}$. The footing is subjected to a permanent vertical load. The model geometry is shown in Figure 2. In a shallow foundation bearing capacity analysis, compared to the other parameters included in the analysis, the angle of internal friction is the dominant parameter that influences the outcome. Thus, a method suitability assessments were performed based on the results of parametric reliability analyses with variations of its value. All analyses were performed according to Eurocode 7 (EC7) [12], design approach 3 (DA3), such that the design value of the vertical action equals to the design value of the resistance $\left(\mathrm{V}_{\mathrm{d}}=\mathrm{R}_{\mathrm{d}}\right)$.

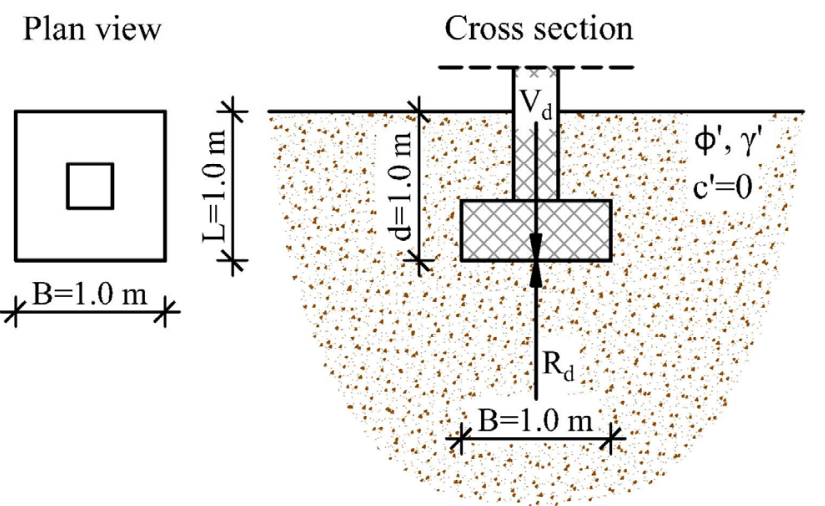

\author{
Symbols: \\ $\gamma^{\prime}$ - effective unit weight of soil \\ $\mathrm{c}^{\prime}$ - cohesion intercept in terms of effective stress \\ $\phi^{\prime}$ - angle of internal friction in terms of effective stress \\ B - foundation width \\ $\mathrm{L}$ - foundation length \\ $\mathrm{d}$ - foundation embedment depth \\ $\mathrm{V}_{\mathrm{d}}$ - design value of vertical action \\ $R_{d}$ - design value of the resistance to action
}

Figure 2. Reliability analyses geometry model.

The value of $V_{d}$ is calculated using the following equation [12]:

$$
\mathrm{V}_{\mathrm{d}}=\gamma_{\mathrm{G}} \cdot \mathrm{V}_{\mathrm{g}}
$$

where:

$\mathrm{V}_{\mathrm{g}}$-is the permanent vertical force

$\gamma_{\mathrm{G}}$-is the partial factor for permanent action, according to EC7, DA3 $\gamma_{\mathrm{G}}=1.35$

In reliability analyses, the following assumptions were introduced:

- $\quad \phi^{\prime}, \gamma^{\prime}$ and $V_{g}$ are random variables that follow normal distribution $[13,14]$ 
- $\quad \phi^{\prime}$ and $\gamma^{\prime}$ are positive correlated, $\mathrm{V}_{\mathrm{g}}$ is uncorrelated with $\phi^{\prime}$ and $\gamma$

- foundation soil is non-cohesive, homogeneous and isotropic

- no presence of groundwater in the soil

Since the statistical scatter of geometric parameters is negligible compared to the scatter of geotechnical parameters and actions $[15,16]$, they are introduced into the calculation as deterministic variables. According to $[13,14]$, the $\phi^{\prime}$ and $\gamma$, and according to [17], $\mathrm{V}_{\mathrm{g}}$ can be considered as random variables with normal PDF. Statistical characteristics of random variables are shown in Table 3, and their mean values used in parametric reliability analyses in Table 4 . The values of the coefficients of variation for random variables $\left(\mathrm{COV}_{\phi^{\prime}}, \mathrm{COV}_{V_{g^{\prime}}} \mathrm{COV}_{\gamma^{\prime}}\right)$ were chosen from literature. Phoon and Kulhawy [18] analyse variability in soil parameters, and they conclude that for soils with internal friction angles between $20^{\circ}$ and $40^{\circ}, \mathrm{COV}_{\phi^{\prime}}$, is within the range of 0.05-0.15. A slightly wider $\mathrm{COV}_{\phi^{\prime}}$ range, $0.05-0.2$, is presented by Phoon [19], with the value depending on how the parameter is determined. Lee et al. recommend the use of $\mathrm{COV}_{\phi^{\prime}}=0.1$ [20] and the same value is used by Sujith et al. [21] in reliability analyses of cantilever reinforced concrete (RC) retaining walls.

Table 3. Statistical characteristics of random variables.

\begin{tabular}{cccc}
\hline Parameter & Designation & Distribution & Coefficient of Variation (COV) \\
\hline$\phi^{\prime}$ & $\mathrm{X}_{1}$ & Normal & 0.1 \\
$\mathrm{~V}_{\mathrm{g}}$ & $\mathrm{X}_{2}$ & Normal & 0.1 \\
$\gamma^{\prime}$ & $\mathrm{X}_{3}$ & Normal & 0.05 \\
\hline
\end{tabular}

Table 4. The mean values of random variables used in parametric reliability analyses.

\begin{tabular}{ccc}
\hline $\left.\boldsymbol{\phi}_{\mathbf{m}}{ }^{\circ}\right]$ & $\mathbf{V}_{\mathbf{g}, \mathbf{m}}[\mathbf{k N}]$ & $\gamma_{\mathbf{m}}^{\prime}\left[\mathbf{k N} / \mathbf{m}^{3}\right]$ \\
\hline 28 & 184.1 & 17.8 \\
32 & 276.3 & 18.5 \\
36 & 424.1 & 19.3 \\
40 & 669.6 & 20.1 \\
44 & 1096.5 & 20.9 \\
\hline
\end{tabular}

The typical value range for the coefficient of variation of soil unit weight $\left(\mathrm{COV}_{\gamma}\right)$ is 0.03-0.07 [6]. Regarding the permanent load variability, various authors [9,22-24] use the value $\mathrm{COV}_{\mathrm{V}_{\mathrm{g}}}=0.1$ in reliability analyses, therefore the same value was chosen for the analyses at issue.

In the parametric reliability analysis, the varied value is $\phi_{\mathrm{m}}{ }^{\prime}$, and the $\gamma_{\mathrm{m}}{ }^{\prime}$ values are calculated from the correlative relation of $\gamma^{\prime}$ and $\phi^{\prime}$ according to [25]. The $\mathrm{V}_{\mathrm{g}, \mathrm{m}}$ values is determined from the condition that $\mathrm{V}_{\mathrm{d}}=\mathrm{R}_{\mathrm{d}}$.

In calculations carried out according to Eurocode 7, the values of geotechnical parameters and actions will be characteristic or design. The characteristic values of $\phi^{\prime}$ and $\gamma$ can be determined using statistical methods, based on available test results. Characteristic values are calculated from $\mathrm{x}_{\mathrm{m}}$ and $\mathrm{COV}_{\mathrm{x}}$ according to [26]:

$$
x_{k}=x_{m} \cdot\left(1-\frac{\operatorname{COV}_{x}}{2}\right),
$$

where:

$\mathrm{x}_{\mathrm{m}}$-is the mean value of $X$

$\mathrm{COV}_{\mathrm{X}}$-is the coefficient of variation of $\mathrm{X}$

From the characteristic values, the design values are calculated in accordance with EC7, DA3. The flow chart for determining the values of geotechnical parameters is shown in Figure 3. It is assumed that the characteristic value of permanent action corresponds to the mean value due to its low variability $[17,24,27,28]$. 


\begin{tabular}{|c|c|c|c|c|}
\hline $\begin{array}{l}\text { MEAN VALUE } \\
\text { OF SOIL }\end{array}$ & (Schr & $\begin{array}{l}\text { CHARACTERISTIC } \\
\text { VALUE OF SOIL }\end{array}$ & EC & $\begin{array}{l}\text { DESIGN VALUE } \\
\text { OF SOIL }\end{array}$ \\
\hline $\begin{array}{c}\text { PARAMETER } \\
\mathrm{x}_{\mathrm{m}}\end{array}$ & & $\begin{array}{c}\text { PARAMETER } \\
\mathrm{x}_{\mathrm{k}}\end{array}$ & - & $\begin{array}{c}\text { PARAMETER } \\
\mathrm{x}_{\mathrm{d}}\end{array}$ \\
\hline
\end{tabular}

Figure 3. Flowchart for geotechnical parameter values calculation.

\subsection{Performance Function}

In general, the performance function in the structural reliability analysis is defined as follows [10]:

$$
\mathrm{g}=\mathrm{R}-\mathrm{S},
$$

$\mathrm{R}=\mathrm{r}(\mathbf{r})$-is resistance function, $\mathbf{r}$ represents set of resistance variables

$\mathrm{S}=\mathrm{s}(\mathbf{s})$-is resistance function, $\mathbf{s}$ represents set of load variables

In the case of a shallow foundation, $R$ and $S$ can be expressed as follows [12]:

$$
\begin{gathered}
\mathrm{S}=\mathrm{V}_{\mathrm{d}}=1.35 \cdot \mathrm{V}_{\mathrm{g}}=1.35 \cdot \mathrm{X}_{2} \\
\mathrm{R}=\mathrm{R}_{\mathrm{d}}=\mathrm{A}^{\prime} \cdot\left(\mathrm{c}^{\prime} \mathrm{N}_{\mathrm{c}} \mathrm{b}_{\mathrm{c}} \mathrm{s}_{\mathrm{c}} \mathrm{i}_{\mathrm{c}}+\mathrm{q}^{\prime} \mathrm{N}_{\mathrm{q}} \mathrm{b}_{\mathrm{q}} \mathrm{s}_{\mathrm{q}} \mathrm{i}_{\mathrm{q}}+0.5 \gamma^{\prime} \mathrm{B}^{\prime} \mathrm{N}_{\gamma} \mathrm{b}_{\gamma} \mathrm{s}_{\gamma} \mathrm{i}_{\gamma}\right),
\end{gathered}
$$

where:

$\mathrm{N}_{\mathrm{c}}, \mathrm{N}_{\mathrm{q}}, \mathrm{N}_{\gamma}$-are bearing capacity factors

$\mathrm{b}_{\mathrm{c}}, \mathrm{b}_{\mathrm{q}}, \mathrm{b}_{\gamma}$-are the base inclination factors

$\mathrm{s}_{\mathrm{c}}, \mathrm{s}_{\mathrm{q}}, \mathrm{s}_{\gamma}$-are the shape factors

$\mathrm{i}_{c}, \mathrm{i}_{\mathrm{q}}, \mathrm{i}_{\gamma}$-are the inclination factors

$\mathrm{q}^{\prime}-$ is the design effective overburden pressure at the level of foundation base

$\mathrm{B}^{\prime}$ - is the effective foundation width

Equations for the " $\mathrm{N}$ ", " $\mathrm{b}$ ", " $\mathrm{s}$ " and " $\mathrm{i}$ " coefficients used for performance function definition were taken from Eurocode 7 [12]. By including Equations (8) and (9) in 7 the following expression for the performance function in $\mathrm{X}$ space yields:

$$
\left(X_{1}, X_{2}, X_{3}\right)=B^{2} X_{3}\left\{\mathrm{~d} \cdot \mathrm{e}^{\pi \tan X_{1}} \tan ^{2}\left(45^{\circ}+X_{1} / 2\right)\left(1+\sin X_{1}\right)+0.7 B\left(e^{\pi \tan X_{1}} \tan ^{2}\left(45^{\circ}+\frac{X_{1}}{2}\right)-1\right) \tan X_{1}\right\}-X_{2}
$$

To simplify the reliability analysis, random variables $X_{1}, X_{2}$ and $X_{3}$ are transformed from the space of real random variables ( $X$ space) to the standard normal space (U space) using the Rosenblatt transformation [29]. By applying the transformation, the performance function in U space yields:

$$
\begin{gathered}
\mathrm{g}\left(\mathrm{U}_{1}, \mathrm{U}_{2}, \mathrm{U}_{3}\right)=\mathrm{B}^{2}\left(\mu_{3}+\sigma_{3} \mathrm{U}_{3}\right)\left\{\mathrm{d} \cdot \mathrm{e}^{\pi \tan \left(\mu_{1}+\sigma_{1} \mathrm{U}_{1}\right)} \tan ^{2}\left(45^{\circ}+\left(\mu_{1}+\sigma_{1} \mathrm{U}_{1}\right) / 2\right)\left(1+\sin \left(\mu_{1}+\sigma_{1} \mathrm{U}_{1}\right)\right)+\right. \\
\left.0.7 \mathrm{~B}\left(\mathrm{e}^{\pi \tan \left(\mu_{1}+\sigma_{1} \mathrm{U}_{1}\right)} \tan ^{2}\left(45^{\circ}+\frac{\left(\mu_{1}+\sigma_{1} \mathrm{U}_{1}\right)}{2}\right)-1\right) \tan \left(\mu_{1}+\sigma_{1} \mathrm{U}_{1}\right)\right\}-\left(\mu_{2}+\sigma_{2} \mathrm{U}_{2}\right),
\end{gathered}
$$

\subsection{Reliabilty Integral}

The integrand of the reliability integral is a joint probability density function (PDF) of random variables. According to the assumptions of the random variable's statistical distribution, the joint PDF is multivariate normal PDF, defined in U space as follows:

$$
\Phi_{\mathrm{u}}(\mathrm{u})=\prod_{\mathrm{i}=1}^{3} \frac{1}{\sqrt{2 \pi}} \exp \left(-\frac{1}{2} \mathrm{u}_{\mathrm{i}}^{2}\right)
$$

By combining Equations (4) and (12), the reliability integral takes the following form:

$$
\Phi(\mathrm{u})=\iiint_{\mathrm{g}(\mathrm{u} 1, \mathrm{u} 2, \mathrm{u} 3)<0} \prod_{\mathrm{i}=1}^{3} \frac{1}{\sqrt{2 \pi}} \exp \left(-\frac{1}{2} \mathrm{u}_{\mathrm{i}}^{2}\right) \mathrm{du}_{1} \mathrm{du}_{2} \mathrm{du}_{3},
$$




\subsection{Defining the Error of the Reliability Method}

The error of the method is defined as the maximum of the absolute difference between $\beta$ calculated using the control method and the one calculated using the method whose accuracy is being assessed:

$$
\mathrm{E}=\max \left(\left|\beta-\beta_{\mathrm{c}}\right|\right),
$$

where:

$\beta$-is the reliability index calculated using the method whose accuracy is being assessed $\beta_{\mathrm{c}}$-is the reliability index calculated using the control method

In Equation (14), the maximum refers to the greatest error from the results of the parametric reliability analyses. The Direct Integration method was chosen as the control method.

\subsection{The Criterion for the Estimation of the Suitability of Reliability Methods}

To define the criterion for the estimation of the suitability of reliability methods, the classification of a structure's expected performance level according to the reliability index was used [16]. Concerning the $\beta$ value, 7 classes of structure expected performance levels are defined: from Hazardous for $\beta=1$, to High for $\beta=5$.

Based on the classification, the size of the acceptable reliability method error $\left(\epsilon_{\mathrm{T}}\right)$ is defined as half the width of the class in which the accurate value $\beta$ is located. Accordingly, the following applies: for $0 \leq \beta<3, \epsilon_{\mathrm{T}}=0.25$, and for $\beta \geq 3, \epsilon_{\mathrm{T}}=0.5$. Meeting these criteria will ensure a $50 \%$ probability that the reliability index (including error) is within the calculated class of the expected performance level, along with the largest error in the classification for a 1 class (Table 5).

Table 5. Expected performance level according reliability indexes [16].

\begin{tabular}{ccc}
\hline Expected Performance Level & $\boldsymbol{\beta}$ & Probability of Unsatisfactory Performance \\
\hline High & 5.0 & $3 \times 10^{-7}$ \\
Good & 4.0 & $3 \times 10^{-5}$ \\
Above average & 3.0 & 0.01 \\
Below average & 2.5 & 0.06 \\
Poor & 2.0 & 0.023 \\
Unsatisfactory & 1.5 & 0.07 \\
Hazardous & 1.0 & 0.16 \\
\hline
\end{tabular}

\subsection{Short Overview of Reliability Methods}

Reliability analyses using the FOSM analytical, Taylor Series, FORM and Simplified FORM methods were conducted using algorithms developed in Matlab programing language, while the Monte Carlo simulations were conducted in an application developed in the c\# programming language. All of the used algorithms are validated by the computer program " $\mathrm{Rt}$ " [30]. Compared to " $\mathrm{Rt}$ ", the developed algorithms are adapted to the problem in question, simplified in data input, include the calculation of the design value of permanent vertical action according to Eurocode 7, and provide additional possibilities when printing out the results. The algorithm used for conducting the Monte Carlo simulations is optimized for quicker execution and additional printing possibilities, e.g., the graphic representation of the histogram of the performance function and the dependence of the $\mathrm{COV}_{\mathrm{pf}}$ value to the number of simulations. Direct integration was performed using an algorithm developed in the $c \#$ programming language and .NET Core framework. Analyses done using the Analytical FOSM, Taylor Series and PEM methods were performed with the assumptions that the FS follows both normal and lognormal distribution. The following abbreviated notation was adopted for easier assumption recognition: normally distributed FS-method name N; lognormally distributed FS—method name LN. 


\subsubsection{Analytical First Order Second Moment (FOSM) and Taylor Series}

Analytical FOSM and the Taylor Series methods belong to the FOSM method group. Only the first terms of a Taylor series expansion of the performance function are used. They are used to estimate the expected value (Equation (15)) and variance (Equation (16)) of the performance function (F). If the number of uncertain variables is $\mathrm{N}$, this method requires evaluating $\mathrm{N}$ partial derivatives of the performance function [3]. The expressions for expected value and variance are defined as follows:

$$
\begin{gathered}
\mathrm{E}[\mathrm{F}]=\mu_{\mathrm{F}} \approx \mathrm{F}\left(\mathrm{X}_{1}, \mathrm{X}_{2}, \ldots, \mathrm{X}_{\mathrm{n}}\right) \\
\sigma_{\mathrm{F}}^{2} \approx \sum_{\mathrm{i}=1}^{\mathrm{n}}\left(\frac{\partial \mathrm{F}}{\partial \mathrm{x}_{\mathrm{i}}}\right)^{2} \sigma_{\mathrm{x}_{1}}^{2}
\end{gathered}
$$

With calculated mean and variance, the reliability index $\beta$ can be determined as follows:

$$
\begin{gathered}
\beta=\frac{E[F]-1}{\sigma_{F}}(F \text { is normally distributed }) \\
\beta=\frac{\ln \left(\frac{E[F]}{\sqrt{1+\sigma_{\mathrm{F}}^{2}}}\right)}{\sqrt{\ln \left(1+\sigma_{\mathrm{F}}^{2}\right)}}(\mathrm{F} \text { is lognormally distributed })
\end{gathered}
$$

The function F could be any relevant function, but for the purposes of this paper it is the factor of safety. The second-moment estimation (Equation (16)) is simplified in Taylor Series methods. It is assumed that this simplification can result in a large error, especially in cases where the $\mathrm{F}\left(\mathrm{X}_{1}, \mathrm{X}_{2}, \ldots, \mathrm{X}_{\mathrm{n}}\right)$ is a mathematically complex function. To estimate the error of FOSM methods without simplification in the second-moment estimation, direct calculation evaluating the partial derivatives with respect to all random variable is performed. In the Taylor Series method, the second-moment is approximated using the following formula:

$$
\sigma_{\mathrm{F}}^{2} \approx=\sum_{\mathrm{i}=1}^{\mathrm{n}}\left(\frac{\Delta \mathrm{F}_{\mathrm{i}}}{2}\right)^{2} ; \Delta \mathrm{F}_{\mathrm{i}}=\left(\mathrm{F}_{\mathrm{i}}^{+}-\mathrm{F}_{\mathrm{i}}^{-}\right)
$$

where:

$\Delta \mathrm{F}_{\mathrm{i}}^{+} / \Delta \mathrm{F}_{\mathrm{i}}^{-}$-FS calculated with the value of $\mathrm{i}^{\mathrm{th}}$ parameter increased/decreased by one standard deviation from its mean value [6].

\subsubsection{Point Estimate Method (PEM)}

PEM is the procedure used for determining the lower order moments of the performance function, done by determining its value on a set of carefully chosen points. The method was first introduced by [31], and the detailed PEM calculation procedure used in this paper is described in [2]. The number of required calculations in a single reliability analysis is $2^{\mathrm{N}}$, where $\mathrm{N}$ is the number of random variables. In these calculations, the value of the factor of safety is calculated with different combinations of random variables values, which are $\mathrm{E}(\mathrm{X})+\sigma_{\mathrm{x}}$ and $\mathrm{E}(\mathrm{X})-\sigma_{\mathrm{X}}\left(\mathrm{E}(\mathrm{X})\right.$ is the expected value, and $\sigma_{\mathrm{X}}$ is the standard deviation of random variable $X)$. The result is the reliability index $\beta$, which is calculated based on the assumption of statistical distribution of the FS.

\subsubsection{First Order Reliability Method (FORM)}

Unlike the FOSM methods, the FORM method includes information on the probability density function (PDF) of all random variables, and the limit state function is expanded at the point on failure surface, instead of the point where all variables have a mean value. The method represents an iterative procedure of searching for the point with the greatest probability density which is located on the failure surface. This point is called the most probable point (MPP), and it is used for the approximation of the performance functions [30]. Random variables need to be transformed into uncorrelated standard 
normal variables, while the limit state function is transformed into standard normal space. The reliability index is then defined as the shortest distance from the origin to the failure surface $(\mathrm{g}(\mathrm{U})=0)$ in standard normal space (Figure $4 \mathrm{a}$ ).

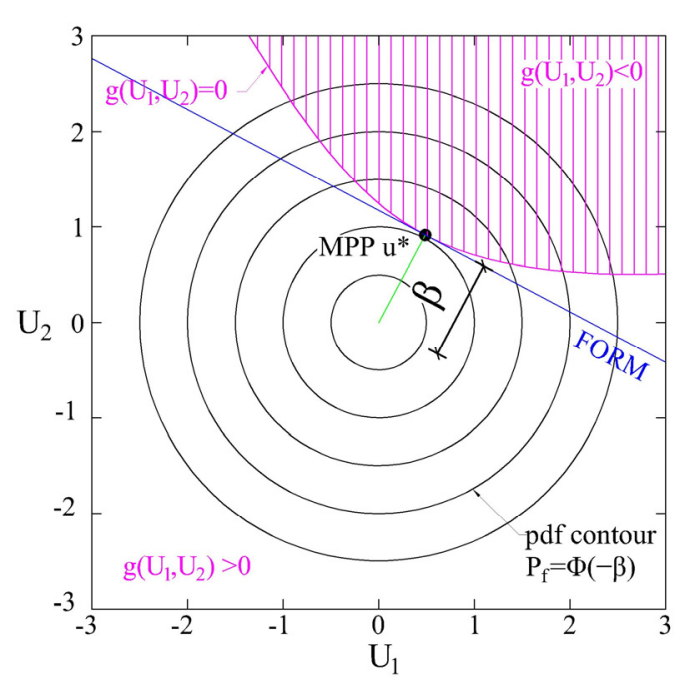

(a)

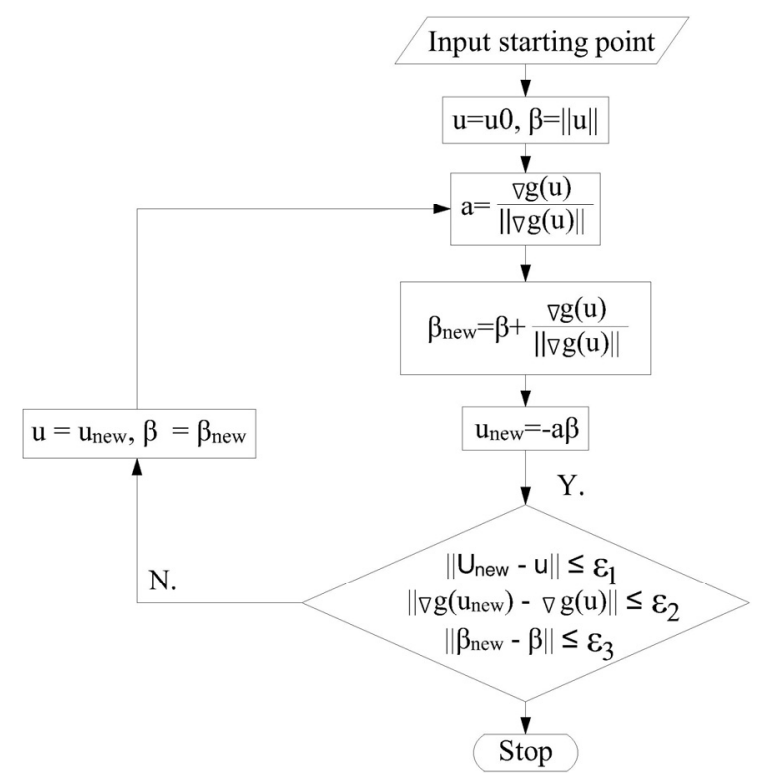

(b)

Figure 4. (a) Geometrical representation of the reliability index in First Order Reliability Method (FORM); (b) The iterative procedure for reliability index calculation using FORM [32].

An iterative procedure (Newton-Rapson algorithm), shown in Figure 4b, was used to calculate the reliability index. The iterative procedure was repeated until all three conditions were met in terms of error size: $\epsilon_{1}, \epsilon_{2}, \epsilon_{3}<10^{-5}$ (Figure $4 \mathrm{~b}$ ).

\subsubsection{Simplified FORM}

The calculation procedure, according to the Simplified FORM method used in this paper, is described in detail in [2]. It consists of three main parts. The first part is an iterative procedure in which the value of the reliability index is assumed, to calculate the reduced values of parameters. The factor of safety is then calculated using the reduced values. The procedure is repeated until the value $\beta$ for which FS $=1$ is found. In the second step, the change of FS for a given change in each set of random variables is determined. Each variable value from the set of values obtained in the final iteration of the first step is increased or decreased by $10 \%$. The variable values related to capacity are increased, while the ones related to demand are reduced [1]. The gradients obtained are then used to calculate the coefficient $\alpha$, which is the base for modifying the variable values used in step 3. The final, third step is an iterative procedure similar to the first step, with the intention of finding $\beta$ for which FS $=1$ applies. The difference from the first step is that the input parameter values were calculated using the $\alpha$ value calculated in the previous step. The resulting $\beta$ represents the reliability index. Iterative procedures from steps one and three stop when the following criteria are satisfied: $\left|\mathrm{FS}-1<10^{-4}\right|$.

\subsubsection{The Monte Carlo Method}

Monte Carlo simulation (MCS) is a numerical process of repeatedly calculating a mathematical or empirical operator in which the variables within the operator are sampled according to the prescribed probability distributions [33]. The expected $\mathrm{p}_{\mathrm{f}}$ values in the researched examples are in the order of magnitude $10^{-3}$; therefore, a relatively large number of simulations is required to achieve satisfactory result accuracy. The coefficient of variation is calculated according to the procedure defined in [34]. Random values were 
generated using the Mersenne Twister 19,937 algorithm from the open (MIT/x11 License) library of MathNet [35].

\subsubsection{Direct Integration Method}

The reliability integral (Equation (13)) is approximated by the Riemann sum [36]. Integration boundaries for each variable in the standard normal space were defined on a closed interval $[-6,6]$, with the number of discretization levels $m=3000$. Considering the form of the integrand, integration boundaries are determined empirically so that the points in their vicinity make a negligible contribution to the result, also taking into account the recommendation given by Gong et al. [37]. They recommend defining the limits of integration in standard normal space within the $[-5,5]$ range, since this ensures a probability lesser than $5.7 \times 10^{-7}$ for uncertain input parameters to fall outside this range, which they consider to be negligible. The number of numerical integration points for a system with 3 random variables is approximately $2.16 \times 10^{11}$. The detailed integration procedure is described in [37]. Due to such a large number of integration points and mathematical complexity of the reliability integral, the integration was carried out on the computational cluster "Isabella". The cluster was founded in 1971 within the University of Zagreb Computing Centre (SRCE) and it is intended for high-performance computing (HPC) for research projects and education. The individual integration job was divided into segments. Each segment of the calculation was performed on a separate processor in parallel, which significantly accelerated execution time. To verify the direct integration algorithm, its results were compared to the results of the Monte Carlo method with a relatively large number of simulations $\left(\approx 10^{4} / \mathrm{p}_{\mathrm{f}}\right)$. The difference in the results between the two methods was in the 5th decimal place. Due to such a high degree of agreement of the results, it is considered that the direct integration algorithm is sufficiently accurate to assess the error of the other methods.

\section{Results}

\subsection{Statistical Distribution of Factor of Safety (FS)}

The statistical characteristics of FS as a random variable, are analysed using the Monte Carlo method. Results for different internal friction angles are shown in Figure 5. The figure shows histograms based on $10^{5}$ data, along with the best-fit curves of normal and lognormal PDFs. All curves are skewed to the right with a single distinct peak. This type of histogram shape indicates that the data are unlikely to follow a normal distribution.

The deviation of FSs PDF from normal distribution PDF can be seen even more clearly in Figure 6, which shows the relationships between the sample quantiles and quantiles of normal distribution (Q-Q plots). What is apparent is that the points of all the charts shown in Figure 6 follow a distinctly non-linear pattern. The trend of increasing curvature by an increase in the angle of internal friction can also be seen. Such non-linear curve shapes can be explained by the differences between the PDF of normal distribution and the actual PDF of the factor of safety. Normal distribution PDF is symmetric and is defined on the interval $\langle-\infty,+\infty\rangle$. The factor of safety can theoretically take values only from the right half of that interval, from which it follows that the shape of its PDF is necessarily asymmetric.

Compared to the PDF of normal distribution, the best fit lines of lognormal PDF generally better fit the histogram shapes of the FS. This is also visible in Figure 7, which shows the Q-Q plots of lognormal distribution. As in the previous case, a trend of increasing data deviation from the quantile of lognormal distribution with an increase in the internal friction angle can be observed. Plots shown in Figure 7 also show that, up to a specific quantile, points form a linear pattern with the inclination of $45^{\circ}$, which passes through the origin. Within these intervals, sample quantiles match the quantiles of lognormal distribution. Quantiles to which the lognormal Q-Q plots are linear are shown in Table 6. 

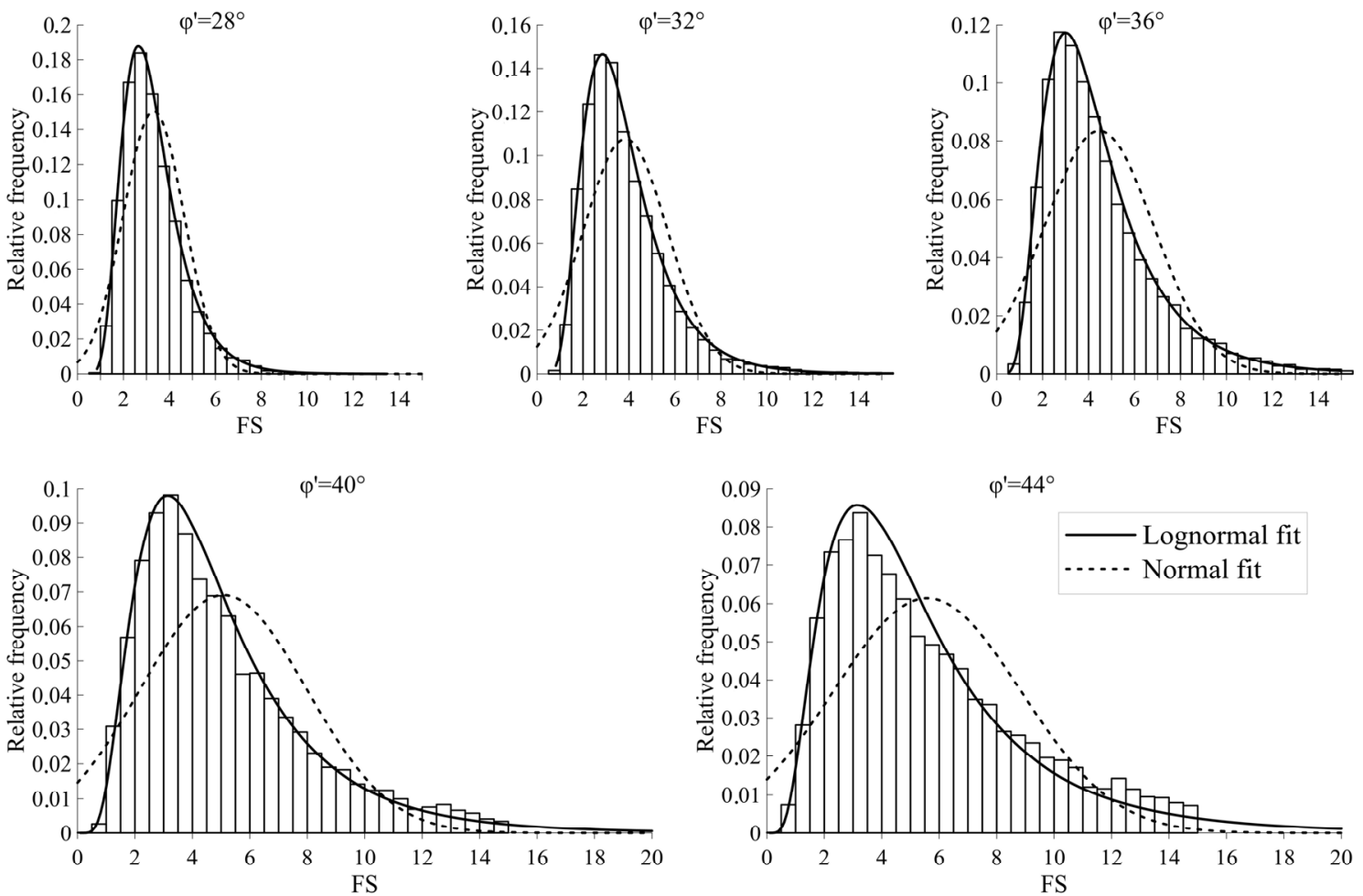

Figure 5. The factor of safety histograms for different $\phi^{\prime}$, along with theoretical best-fit curves of normal and lognormal distribution.
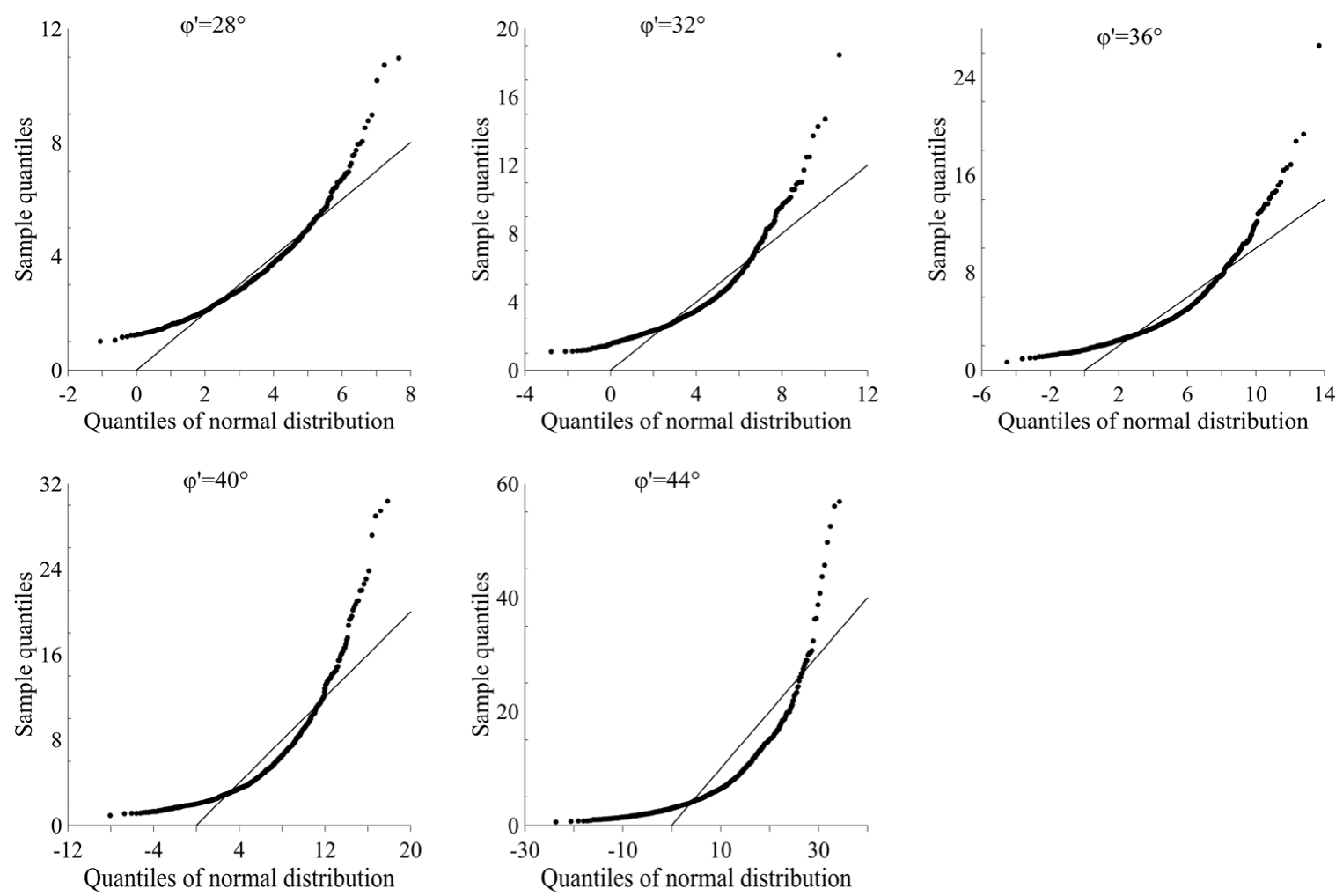

Figure 6. Quantiles and quantiles (Q-Q) plots of normal distribution. 

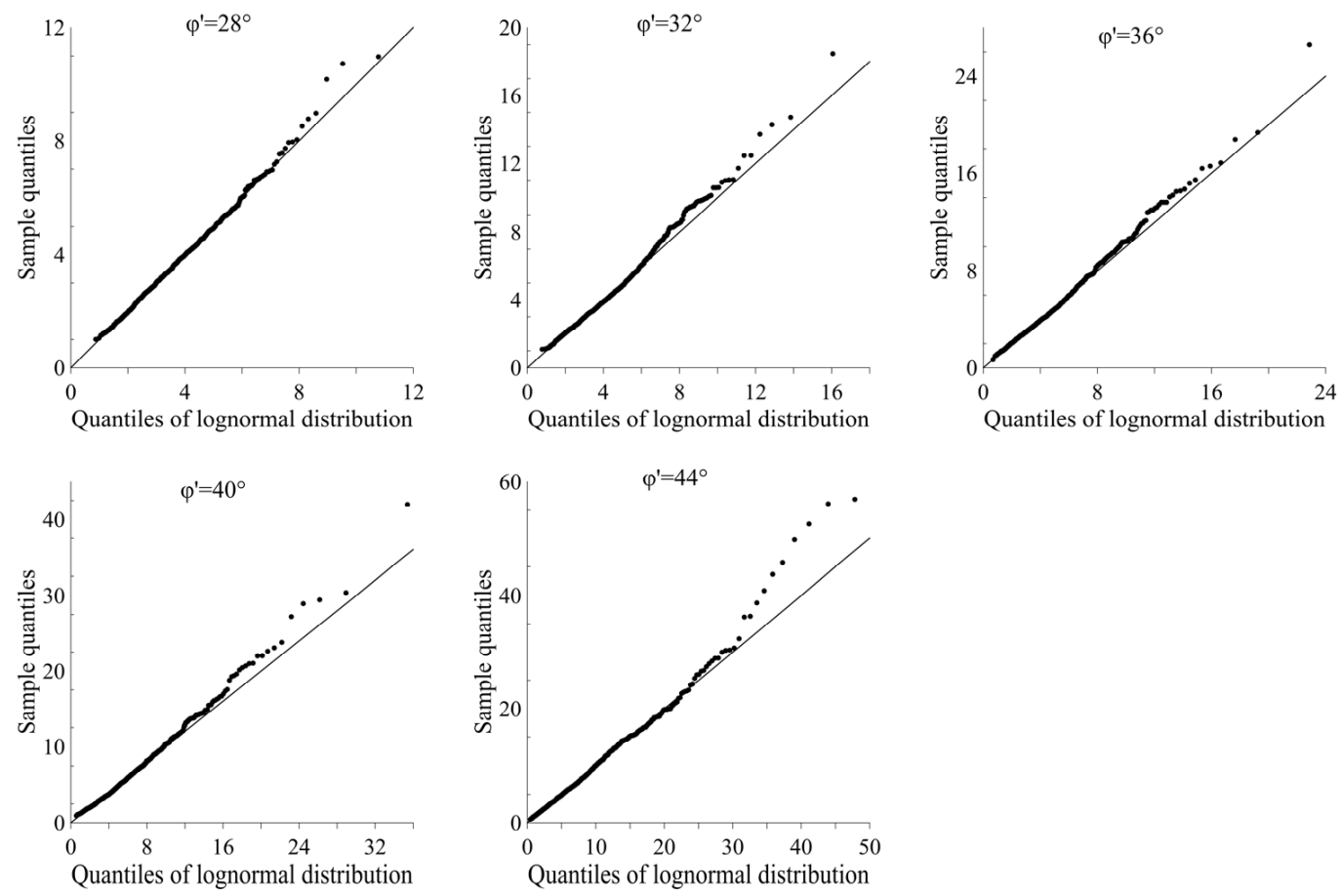

Figure 7. Q-Q plots of lognormal distribution.

Table 6. Quantiles to which the lognormal Q-Q plots are linear.

\begin{tabular}{ccc}
\hline $\boldsymbol{\phi}\left[^{\circ}\right]$ & $\begin{array}{c}\text { Quantiles to which the Lognormal Q-Q } \\
\text { Plots are Linear }(\mathbf{X})\end{array}$ & $\begin{array}{c}\text { Cumulative Density } \\
\text { Function at } \mathbf{X}\end{array}$ \\
\hline 28 & 7.0 & 0.98 \\
32 & 7.3 & 0.95 \\
36 & 9.2 & 0.94 \\
40 & 11.9 & 0.93 \\
44 & 17.1 & 0.93 \\
\hline
\end{tabular}

Table 6 illustrates that the quantiles to which the lognormal Q-Q plot is linear are within the range of FSs commonly used in everyday engineering practices. It also shows that the cumulative density function $(\mathrm{CDF})$ values at $\mathrm{X}$ are within the interval of $0.93-0.98$. After the linear part, the points form a convex curve located above the line. This phenomenon is the result of a thicker tail of the actual PDF of the FS compared to the PDF of lognormal distribution. It can be concluded that the actual PDF of FS is not lognormal, but it shows a good agreement with it for a significant part of the curve.

Figure 8 shows the results of reliability analysis obtained using lognormal and normal PDFs of FS from Figure 6 along with results of Direct Integration. The results of Direct Integration are presented to evaluate errors caused by an incorrect assumption of the FS distribution. The pf values of the $\mathrm{CP} 1$ and $\mathrm{CP} 2$ curves represent the areas below the best-fit PDFs (normal and lognormal) shown in Figure 5, considering only the following interval $\langle-\infty, 1\rangle$. The common feature of all three curves is the trend of increasing probability of failure with increasing $\phi^{\prime}$, or the reverse relationship in the case of the reliability index. The average error value expressed by $\beta$ in the case of normal distribution is 1.40 , and for lognormal considerably less, 0.06 . 

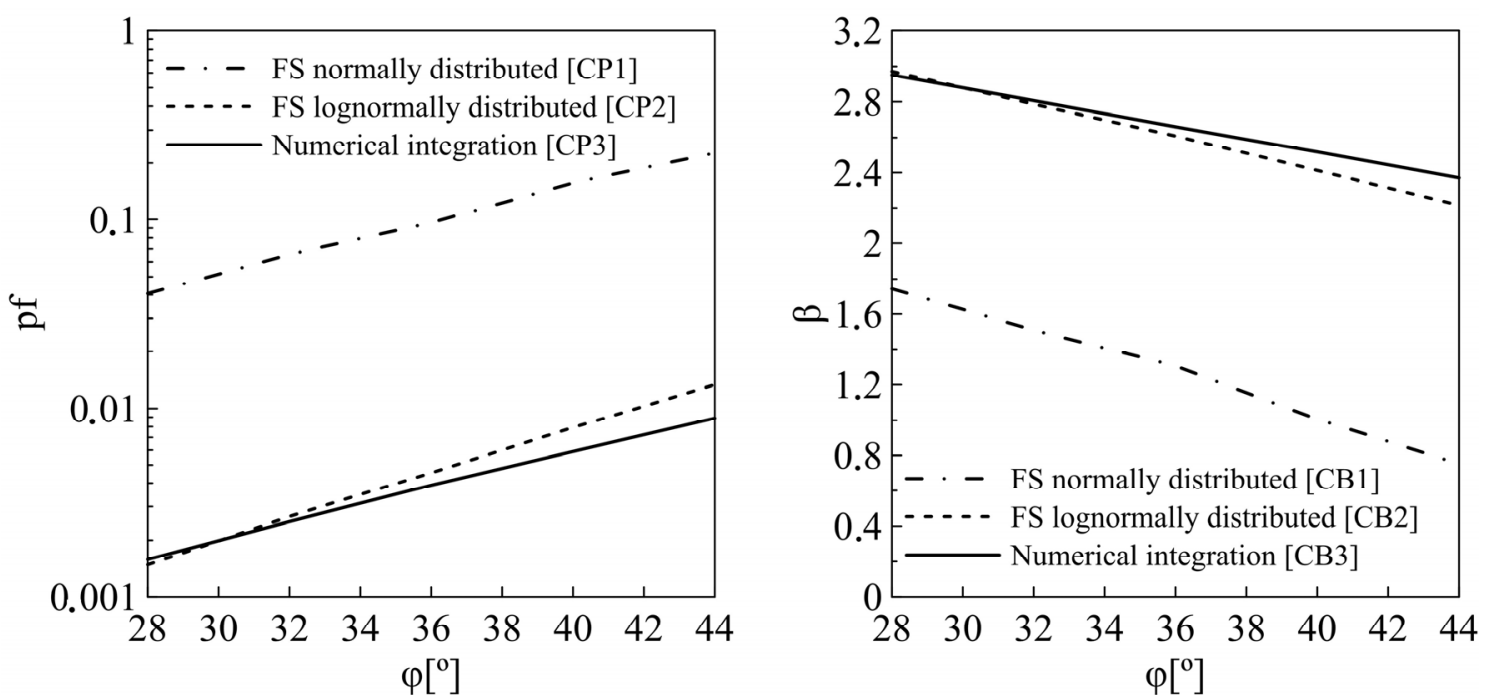

Figure 8. Comparison of pf and $\beta$ calculated with the assumption that FS is normal and lognormal along with the results of Direct Integration of reliability integral.

\subsection{The Results of Reliability Methods}

The summary of reliability analyses performed by different methods is shown in Figure 9. In general, the errors of the Taylor Series and PEM methods are significantly higher, compared to other methods. Analytical FOSM, Taylor Series and PEM with the assumption that FS is normally distributed result in the highest errors, with values within the range of $0.91-1.87$. The same methods result in a considerably less error, 0.06-0.6, when it was assumed that the FS is lognormally distributed. The results of direct integration, Monte Carlo, FORM and Simplified FORM methods are in very good agreement, with the maximum error of 0.05 . The trend of decreasing the reliability index with an increase in the internal friction angle is visible in all cases. All methods except the PEM, with the assumption that the FS follows lognormal distribution, are below the control curve, i.e., give a conservative estimate of the reliability index.

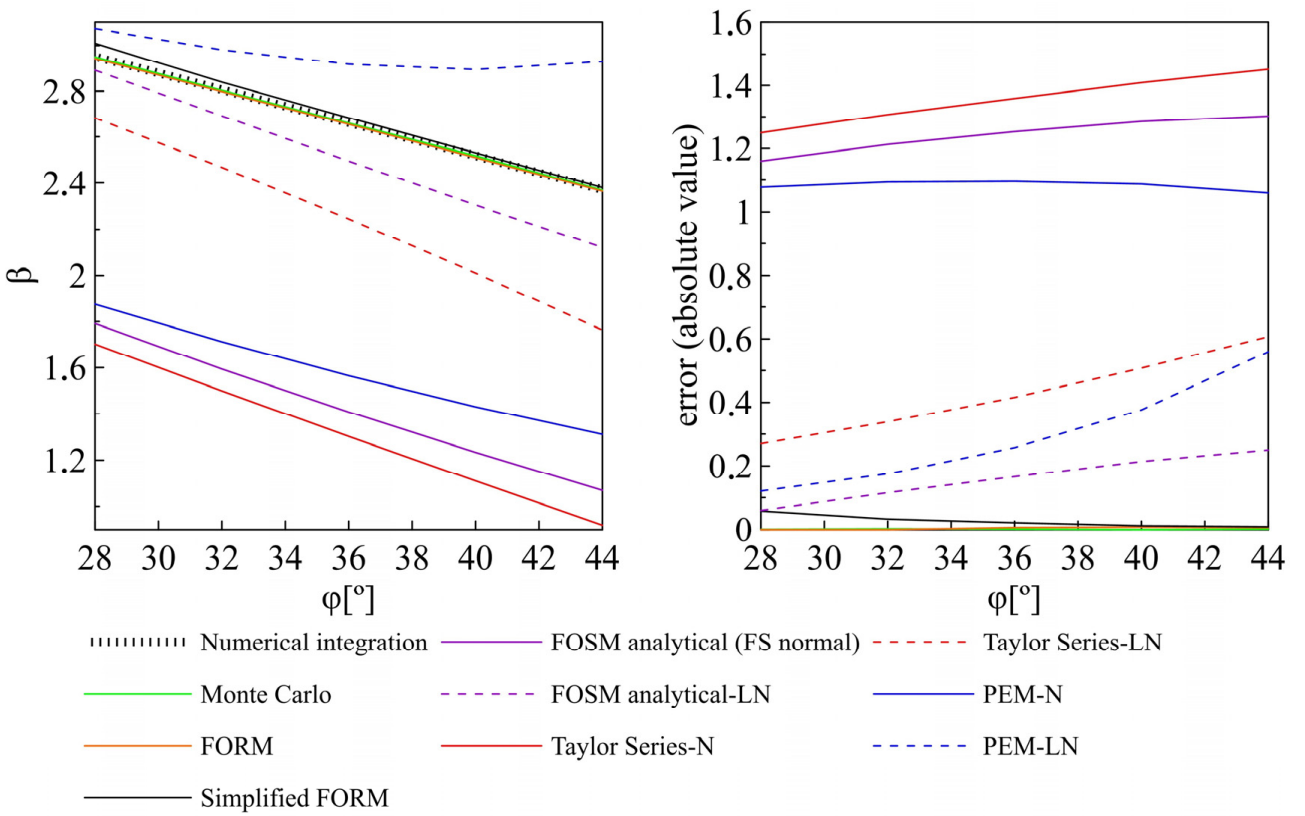

Figure 9. Summary of reliability analysis performed by different methods. 


\subsubsection{Monte Carlo Method}

The results of the Monte Carlo method shown in Figure 10 were obtained from a relatively large number of simulations $\left(10^{7}\right)$ compared to the pf $\left(\approx 10^{-3}\right)$, which resulted in a low maximum error of $\approx 0.1 \%$. The number of simulations is directly related to the error of the results; therefore, its influence on $\mathrm{COV}_{\mathrm{p}_{\mathrm{f}}}$ was analysed (Figure 10).

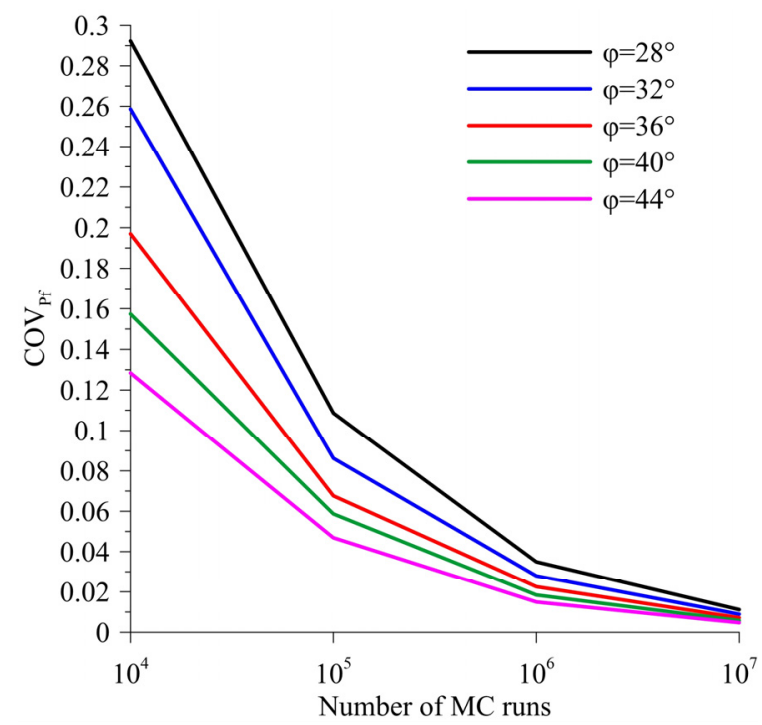

Figure 10. Relationship between the $\mathrm{COV}_{\mathrm{p}_{\mathrm{f}}}$ and number of Monte Carlo (MC) runs.

The statement according to which $\approx 10 / \mathrm{p}_{\mathrm{f}}$ simulation is required for $\mathrm{COV}_{\mathrm{p}_{\mathrm{f}}}$ to be less than 0.3 [7] matches the results shown in Figure 10. The maximum value of $\mathrm{COV}_{\mathrm{p}_{\mathrm{f}}}$ for the number of simulations of $\approx 10 / \mathrm{p}_{\mathrm{f}}$ is 0.29 , which confirms the statement. Increasing the number of simulations to $100 / \mathrm{p}_{\mathrm{f}}$ results in a decrease in $\mathrm{COV}_{\mathrm{p}_{\mathrm{f}}}$ from an average of 0.2 to 0.07 . Further increase of the number of simulations to $1000 / \mathrm{p}_{\mathrm{f}}$ and $10000 / \mathrm{p}_{\mathrm{f}}$ reduces the $\mathrm{COV}_{\mathrm{p}_{\mathrm{f}}}$ to 0.008 and 0.005 , respectively.

\subsubsection{FORM and Simplified FORM}

The average reliability index error calculated by the FORM method is 0.008 . Its value depends on the accuracy of the iterative procedure of searching for the MPP location. The procedure is stopped when the criteria related to $\epsilon_{1}, \epsilon_{2}, \epsilon_{3}$ (Figure 5) values are satisfied. Regarding this, the criteria were defined as follows: $\epsilon_{1}, \epsilon_{2}, \epsilon_{3}<10^{-5}$. Meeting them took performing 8-9 iterations per analysis. According to expectations, the FORM curve is slightly below the control curve (Figure 10), which is a consequence of the performance function approximation by the first-order curve.

The Simplified FORM method curve also matches well with the control method, with an average error of 0.03 . High accuracy was achieved due to the strict conditions which were set regarding the error of the two iterative procedures performed within the method. These procedures aim to calculate the reliability index for which FS equals one. The stopping criteria is set as follows: $\left|\mathrm{FS}-1<10^{-4}\right|$. It took approximately 2000 iterations in a single analysis to meet the criteria.

\subsubsection{FOSM and Point Estimate Method (PEM)}

Compared to other reliability methods, FOSM analytical, Taylor Series and PEM results in the highest errors, with values in the range of 0.06-1.87, which are shown in Table 7. The lognormal assumption results in an error range within $0.06-0.61$, while normal assumption results in significantly higher errors, ranging from 0.91-1.87 (Figure 9 and Table 7). 
Table 7. Errors of FOSM analytical, Taylor Series and PEM methods.

\begin{tabular}{ccc}
\hline Method & Mean Error [Absolute Value] & Mean Error [\%] \\
\hline FOSM analytical-LN & 0.16 & 6.1 \\
PEM -LN & 0.30 & 11.3 \\
Taylor Series-LN & 0.43 & 16.1 \\
PEM-N & 1.57 & 59.2 \\
FOSM analytical-N & 1.24 & 46.7 \\
Taylor Series-N & 1.30 & 48.9 \\
\hline
\end{tabular}

\subsection{Reliability Methods Suitability Assessment}

Reliability method suitability assessments were performed using the criterion defined in Section 2.4. The results were shown in Tables 8-11. Table 8 shows the results of suitability assessment of the ULS of shallow foundation from this study. Neither of the FOSM methods, except FOSM analytical-LN, satisfy the proposed criterion. More sophisticated methods, such as the Monte Carlo, FORM and Simplified FORM, meet the criterion. Despite the complex formulation of the reliability integral, their error values are negligible.

Table 8. Reliability methods suitability assessment for the case of ULS of shallow foundation according to the proposed criteria.

\begin{tabular}{cccc}
\hline Method & Error (Absolute Value) & Acceptable Error & Meet the Criteria \\
\hline Monte Carlo & $3 \times 10^{-3}$ & & Yes \\
FORM & $8 \times 10^{-3}$ & & Yes \\
Simplified FORM & 0.05 & & Yes \\
FOSM analytical-LN & 0.16 & 0.25 & Yes \\
PEM-N & 0.29 & & No \\
Taylor Series-LN & 0.42 & No \\
PEM-N & 1.08 & No \\
FOSM analytical-N & 1.24 & No \\
Taylor Series-N & 1.35 & No \\
\hline
\end{tabular}

Table 9. Reliability methods suitability assessment in the case of stability of embankments [1] according to the proposed criteria.

\begin{tabular}{ccccccc}
\hline \multirow{2}{*}{ Method } & \multicolumn{3}{c}{ CASE 1 $^{\mathbf{1}}$} & \multicolumn{3}{c}{ CASE 2 2 $^{\text {2 }}$} \\
\cline { 2 - 6 } & $\begin{array}{c}\text { Error } \\
\text { (Absolute Value) }\end{array}$ & $\begin{array}{c}\text { Acceptable } \\
\text { Error }\end{array}$ & $\begin{array}{c}\text { Meet the } \\
\text { Criteria }\end{array}$ & $\begin{array}{c}\text { Error } \\
\text { (Absolute Value) }\end{array}$ & $\begin{array}{c}\text { Acceptable } \\
\text { Error }\end{array}$ & $\begin{array}{c}\text { Meet the } \\
\text { Criteria }\end{array}$ \\
\hline Taylor Series-LN & 0.84 & & No & 0.78 & No \\
Taylor Series-N & 0.48 & 0.25 & No & 1.00 & No & No \\
PEM-N & 0.27 & & No & 1.19 & 0.5 & Yes \\
Simplified FORM & 0.13 & & Yes & 0.03 & \\
\hline
\end{tabular}

${ }^{1}$ Stability of column-supported embankments [1]. ${ }^{2}$ Stability of embankments supported on panels under the side slope [1].

Table 10. Reliability methods suitability assessment in the case of retaining wall [2] according to the proposed criteria.

\begin{tabular}{ccccccc}
\hline \multirow{2}{*}{ Method } & \multicolumn{3}{c}{ Sliding on Sand } & \multicolumn{3}{c}{ Sliding in Clay } \\
\cline { 2 - 7 } & $\begin{array}{c}\text { Error } \\
\text { (Absolute Value) }\end{array}$ & $\begin{array}{c}\text { Acceptable } \\
\text { Error }\end{array}$ & $\begin{array}{c}\text { Meet the } \\
\text { Criteria }\end{array}$ & $\begin{array}{c}\text { Error } \\
\text { (Absolute Value) }\end{array}$ & $\begin{array}{c}\text { Acceptable } \\
\text { Error }\end{array}$ & $\begin{array}{c}\text { Meet the } \\
\text { Criteria }\end{array}$ \\
\hline Simplified FORM & 0.00 & & Yes & 0.02 & Yes \\
Taylor Series-N & 0.38 & 0.25 & No & 0.07 & Yes & No \\
PEM-N & 0.28 & & No & 0.34 & Yes \\
PEM-LN & 0.04 & & Yes & 0.16 & \\
\hline
\end{tabular}


Table 11. Reliability methods suitability assessment in the case of retaining wall [2] according to the proposed criteria.

\begin{tabular}{cccc}
\hline \multirow{2}{*}{ Method } & \multicolumn{3}{c}{ Bearing Capacity (Undrained) } \\
\cline { 2 - 4 } & Error (Absolute Value) & Acceptable Error & Meet the Criteria \\
\hline Simplified FORM & 0.02 & & Yes \\
Taylor Series-N & 0.19 & 0.25 & Yes \\
PEM-N & 0.26 & No \\
PEM-LN & 0.31 & No \\
\hline
\end{tabular}

Similar results were obtained for the reliability methods suitability assessment in the case of the stability of embankments from [1]. The analysis used data from Table 1, and the assessment results were shown in Table 9. As in the case studied by this paper, the control method of choice is the Direct Integration method. The Taylor Series method and the PEM do not meet the criterion, while Simplified FORM does, as in the previous example.

Table 9 shows the results of the reliability method suitability assessment of retaining wall from [2], which used data from Table 2. In this example, Simplified FORM meets the set criterion for all three design situations considered, and PEM-N does not meet the criterion for any of them. The Taylor Series-N meets the criterion in the cases of sliding in clay and bearing capacity but does not meet the criterion for sliding on sand. PEM-LN meets the criterion in the cases of sliding on sand and sliding in clay but does not meet the criterion for bearing capacity.

\section{Discussion}

The paper shows that the FS for the ULS of shallow foundation is neither lognormally nor normally distributed (Figures 5-7), i.e., its actual PDF is unknown. Nevertheless, due to the similarity of the lognormal PDF and the actual PDF of FS, the claim from [1-6] according to which it is reasonable to assume a lognormal distribution of FS may be acceptable for use in everyday engineering practice, under certain conditions-e.g., when used in combination with the Monte Carlo method or Analytical FOSM method (Figures 8 and 9).

The reason for this is a relatively good match between the actual PDF of FS and the PDF of lognormal distribution. For different internal friction angles, good matching of the two PDF curves ranges up to the 98th percentile for $\phi^{\prime}=28^{\circ}$, and the 93rd percentile for $\phi^{\prime}=44^{\circ}$ (Figure 7). These findings are in agreement with the results of the study which analysed the statistic characteristics of the performance functions in the case of ULS and SLS piles [4]. Much like this study, most of the theoretical curve and the actual PDF of FS match well, with larger deviations visible only in their tails. In the case of normally distributed FS, which was used for reliability analyses $[1,2,6]$, the error size is significantly larger. Such a result is expected, since the deviations between the actual PDF of FS and the fitted normal PDF are large (Figures 5 and 6 ). This leads to a conclusion that the dominant cause for error in the Taylor Series and PEM methods arises from the simplification in the mean values and variances of the performance function estimations (Figure 8), and not from an incorrect approximation of the distribution of the performance function. The claim from [3], according to which a lognormal approximation leads to a conservative estimate of the reliability index, partially matches the results of this study, but only with friction angles larger than $30^{\circ}$. Contrary to this, in all analysed cases a normally distributed FS leads to a conservative approximation of $\beta$ (Figure 8).

Figure 9 clearly shows a positive correlation between the reliability index calculated using the methods from the FOSM group and FORM, which matches the data from the study using this correlation for the modification of the $\mathrm{RBO}$ procedure by replacing the FOSM method for FORM [9].

The results of the reliability methods suitability assessments in the case of the ULS of shallow foundation are shown in Table 8. The Monte Carlo method, FORM and Simplified FORM methods result in a negligible error up to 0.05 and FOSM analytical-LN in a slightly 
greater error-up to 0.25 (Figure 10). According to the proposed criterion (Section 2.4), they are suitable for a reliability assessment of the footing researched in this paper. Introducing additional variables, e.g., load eccentricity or soil cohesion, might result in larger errors; with the exception of the Monte Carlo method, their suitability should be checked for shallow foundation reliability analysis in general.

The Taylor series, PEM and FOSM analytical with normally distributed FS result in a large error, ranging from 0.56 to 1.45 . Based on the reliability method suitability assessment, it is concluded that they are not suitable for reliability assessment of the shallow footing researched in this paper. Since the problem researched in the paper is fundamental in the sense of applied load and soil type, the conclusion regarding the Taylor Series, PEM and Analytical FOSM-N can be extended to the reliability analysis of footings in general, also taking into account more complex types of actions and ground layering

For example, a reliability analysis of a footing embedded in coherent soil, loaded with different types of action, will include more random variables, and consequently a mathematically more complex reliability integral formulation. This will affect the shape of the actual PDF of FS and additionally contribute to the uncertainties in the first and second moments estimation.

The results of the reliability method suitability assessment of the ULS of shallow foundation are in agreement with the results of the study dealing with embankment stability [1]. This study concluded that the Taylor Series and PEM methods are not appropriate for the estimation of the reliability of embankment stability and recommends using only the Simplified FORM method (Table 1). It is presumed that such a conclusion was reached based on the error sizes for the methods considered. The criterion defined in Section 2.4 was applied to the data from this study, and the results are shown in Table 9. The results obtained perfectly match the conclusions of the study authors, even though they did not explicitly list the criteria which led to their conclusion.

The same criterion was applied to the data from the study (Table 2) which researched retaining wall reliability for three failure modes: sliding on sand, sliding in clay and bearing capacity (undrained) [2]. Unlike the previous two examples (shallow foundation and embankment stability), the performance functions are significantly simpler, which generally yielded smaller errors for all the methods used (Tables 10 and 11). The Simplified FORM method is suitable for the reliability assessment of all three failure modes, while PEM-N is not suitable for either. The Taylor Series-N method is suitable for reliability analyses of sliding on clay and bearing capacity, while the PEM-LN method is suitable for reliability analyses of sliding on sand and sliding in clay.

Based on the results presented, a conclusion is reached on which methods are suitable for use in the presented geotechnical engineering tasks. In general, simpler methods are not recommended in everyday engineering practice without previous validation in the task at hand. Doing otherwise can lead to incorrect reliability measurements, which will be impossible to identify as an under- or overconservative solution. This is also applicable for more complex reliability analyses, such as the RBO, since these procedures use previously listed methods.

Although not the subject of this paper, the reliability analyses showed significant differences in reliability indexes (ranging from 2.38 to 2.94) of the footing for different angles of internal friction. All analyses were performed for the ULS according to Eurocode 7, DA3, for the case when $E_{d}=R_{d}$. The target $\beta$ value for the reference period of 50 years is 3.8 [17]. Calculated reliability indexes are significantly lower than the recommended value; therefore, a question of design procedures evaluation according to EC7 can be raised. The recommendation for further research is to analyse the reliability indexes of different types of geotechnical structure designed according to Eurocode 7 and the possible introduction of additional partial factors of safety elaboration regarding the degree of understanding of the site-specific conditions. A similar principle is prescribed in the Canadian Highway Bridge Design Code [38], which allows engineers to have their designs reflect the degree of uncertainties associated with the parameters and models used [39]. 
Author Contributions: K.I. and F.D. developed the main concept and conceived the research. F.D. was responsible for algorithms development, charts creation and he drafted the manuscript. K.I. analysed results, contributed to the conclusion and was responsible for English translation. M.S.K. and B.S. critically reviewed manuscript. All authors have read and agreed to the published version of the manuscript.

Funding: This research received no external funding.

Institutional Review Board Statement: Not applicable.

Informed Consent Statement: Not applicable.

Data Availability Statement: The data presented in this study are available on request from the corresponding author.

Acknowledgments: The authors would like to thank Ivan Hip (University of Zagreb, Faculty of Geotechnical Engineering) for the contribution in the numerical integration algorithms development. We also thank Emir Imamagic (University of Zagreb Computing Centre (SRCE)) for providing technical support regarding the analyses performed on computational cluster "Isabella".

Conflicts of Interest: The authors declare no conflict of interest.

\section{References}

1. Filz, G.M.; Navin, M.P. Final Contract Report; Virginia Transportation Research Council: Charlottesville, VA, USA, 2006.

2. Duncan, J.M.; Sleep, D.M. Evaluating Reliability in Geotechnical Engineering. In Risk and Reliability in Geotechnical Engineering; Phoon, K.-K., Ed.; Taylor \& Francis: New York, NY, USA, 2014.

3. Baecher, G.B.; Christian, J.T. Reliability and Statistics in Geotechnical Engineering, 1st ed.; Wiley: Chichester, UK, 2003.

4. Fenton, G.A.; Griffiths, D.V. Risk Assessment in Geotechnical Engineering; Wiley: New Jersey, NJ, USA, 2008.

5. Wang, Y.; Kulhawy, F.H. Reliability Index for Serviceability Limit State of Building Foundations. J. Geotech. Geoenviron. Eng. 2008, 134, 1587-1594. [CrossRef]

6. Duncan, J.M. Factors of Safety and Reliability in Geotechnical Engineering. J. Geotech. Geoenviron. Eng. 2000, 126, 307-316. [CrossRef]

7. Phoon, K.-K. Reliability-Based Design in Geotecnical Engineering, 1st ed.; Taylor \& Francis Geological: New York, NY, USA, 2008.

8. Zhang, L.M.; Ng, A.M.Y. Probabilistic limiting tolerable displacements for serviceability limit state design of foundations. Géotechnique 2005, 55, 151-161. [CrossRef]

9. Zhang, J.; Zhang, L.; Tang, W.H. Reliability-Based Optimization of Geotechnical Systems. J. Geotech. Geoenviron. Eng. 2011, 137, 1211-1221. [CrossRef]

10. Joint Committee on Structural Safety. Probabilistic Model Code Part 1-Basis of Design. 2001. Available online: https://www.jcsslc.org/jcss-probabilistic-model-code/ (accessed on 31 December 2020).

11. Pirić, K. Reliability Analysis in Ship Structural Concept Design. Unpublished Doctoral Thesis, University of Zagreb, Zagreb, Croatia, 2014.

12. European Committee for Standardization. Eurocode 7: Geotechnical Design-Part 1: General Rules (EN 1997-1:2004+AC:2009). 2012. Available online: https:/ /www.google.com.hk/url?sa=t\&rct=j\&q=\&esrc=s\&source=web\&cd=\&ved=2ahUKEwjes4O4 _ZzuAhWPfd4KHdISAzMQFjAAegQIAhAC\&url=https\%3A\%2F\%2Fwww.ngm2016.com\%2Fuploads\%2F2\%2F1\%2F7\%2F9 \%2F21790806\%2Feurocode_7_-_geotechnical_designen.1997.1.2004.pdf\&usg=AOvVaw1zogUKH1d1y31mSAHbDGDc (accessed on 31 December 2020).

13. Lacasse, S.; Nadim, F. Uncertainties in Characterizing Soil Properties. In Uncertainty in the Geologic Environment: From Theory to Practice; ASCE: New York, NY, USA, 1996; pp. 49-75.

14. Forrest, W.S.; Orr, T.L. Reliability of shallow foundations designed to Eurocode 7. Georisk 2010, 4, 186-207. [CrossRef]

15. Gäßler, G. Vernagelte Gelandesprunge-Tragverhalten Und Standsicherheit. Unpublished Ph.D. Thesis, Université de Karlsruhe, Karlsruhe, Germany, 1987.

16. Nottrodt, H.P. Beitrag Zur Einfuhrung Semiprobabilistischer Methoden in Der Geotechnik. Unpublished Ph.D. Thesis, Université de Weimar, Weimar, Germany, 1990.

17. European Committee for Standardization. Eurocode: Basis of Structural Design (EN 1990:2002+A1:2005+A1:2005/AC:2010). 2011. Available online: https://standards.iteh.ai/catalog/standards/cen/20024ae2-74ee-4a88-b584-2443b1cb0630/en-1990-2002-a1 -2005-ac-2010 (accessed on 31 December 2020).

18. Phoon, K.-K.; Kulhawy, F.H. Characterization of geotechnical variability. Can. Geotech. J. 1999, 36, 612-624. [CrossRef]

19. Phoon, K.-K. Role of reliability calculations in geotechnical design. Georisk Assess. Manag. Risk Eng. Syst. Geohazards 2016, 11, 4-21. [CrossRef]

20. Lee, I.K.; Ingles, O.G.; White, W. Geotechnical Engineering; Pitman: Boston, MA, USA, 1983.

21. Sujith, M.S.; Menon, D.; Dodagoudar, G.R. Reliability analysis and design of cantilever RC retaining walls against sliding failure. Int. J. Geotech. Eng. 2011, 5, 131-141. [CrossRef] 
22. Ravindra, M.K.; Galambos, T.V. Load and Resistance Factor Design for Steel. J. Struct. Div. 1978, 104, $1337-1353$.

23. Holicky, M.; Sykora, M. Stochastic Models in Analysis of Structural Reliability. In Proceedings of the International Symposium on Stochastic Models in Reliability Engineering, Life Sciences and Operation Management, Beer Sheva, Israel, 8-11 February 2010; SCE-Shamoon College of Engineering: Beer Sheva, Israel, 2010.

24. Jovanović, B.; Van Coile, R.; Hopkin, D.; Khorasani, N.E.; Lange, D.; Gernay, T. Review of Current Practice in Probabilistic Structural Fire Engineering: Permanent and Live Load Modelling. Fire Technol. 2020. [CrossRef]

25. United States Naval Facilities Engineering Command. Soil Mechanics, Design Manual 7.01, 2nd ed.; Department of the Navy, Naval Facilities Engineering Command: Alexandria, VA, USA, 1986.

26. Schneider, H.R. Definition and Determination of Characteristic Soil Properties. In Proceedings of the Fourteenth International Conference on Soil Mechanics and Foundation Engineering, Hamburg, Germany, 6-12 September 1997; Balkema, A.A., Ed.; BR-3000: Rotterdam, The Netherlands, 1997.

27. Van Coile, R.; Caspeele, R.; Taerwe, L. Reliability-based evaluation of the inherent safety presumptions in common fire safety design. Eng. Struct. 2014, 77, 181-192. [CrossRef]

28. Gernay, T.; Van Coile, R.; Khorasani, N.E.; Hopkin, D. Efficient uncertainty quantification method applied to structural fire engineering computations. Eng. Struct. 2019, 183, 1-17. [CrossRef]

29. Lebrun, R.; Dutfoy, A. Do Rosenblatt and Nataf isoprobabilistic transformations really differ? Probab. Eng. Mech. 2009, 24, 577-584. [CrossRef]

30. Haukaas, T. The Computer Program Rt. Available online: http://terje.civil.ubc.ca/the-computer-program-rt/ (accessed on 31 December 2020).

31. Rosenblueth, E. Point estimates for probability moments. Proc. Natl. Acad. Sci. USA 1975, 72, 3812-3814. [CrossRef] [PubMed]

32. Xiaoping, D. Probabilistic Engineering Design, First Order and Second Reliability Methods, Lecture Notes; University of Missouri: Rolla, MO, USA, 2005.

33. Ang, A.H.-S.; Tang, W.H. Probability Concepts in Engineering: Emphasis on Applications in Civil E Environmental Engineering, 2nd ed.; Wiley: Hoboken, NJ, USA, 2006.

34. Li, W. Appendix B. In Risk Assessment of Power Systems; Wiley: Hoboken, NJ, USA, 2014.

35. Christoph, R. Math.NET Numerics. Available online: https://numerics.mathdotnet.com/ (accessed on 17 September 2020).

36. Calculus, A.H. A New Horizon, 6th ed.; Wiley: New York, NY, USA, 1999.

37. Gong, W.; Juang, C.H.; Martin, J.R. Numerical integration method for computing reliability index of geotechnical system. Georisk Assess. Manag. Risk Eng. Syst. Geohazards 2015, 10, 109-120. [CrossRef]

38. Canadian Standards Organization. Canadian Highway Bridge. Design Code; Canadian Standards Organization: Canada, ON, Canada, 2014.

39. Fenton, G.A.; Naghibi, F.; Dundas, D.; Bathurst, R.J.; Griffiths, D. Reliability-based geotechnical design in 2014 Canadian Highway Bridge Design Code. Can. Geotech. J. 2016, 53, 236-251. [CrossRef] 